\title{
G-Energy: Route to Future Roads
}

\author{
Yash Bhan Singh ${ }^{1}$, Rachna Gera ${ }^{2}$ \\ Poornima Institute of Engineering \& Technology (PIET), Jaipur ${ }^{1,2}$
}

\begin{abstract}
As we move forward with increasing demands of energy generation, it has become very necessary to optimize the systems where in the energy consumption is either very large or is inefficient. The objective of this paper is to provide an overview of how roads of future can be built using self-healing solar technology using phospholipid cells and how the electrical energy transfer will take place using cordless systems for electric vehicles i.e. in-motion charging using green energy as it is known that carbon emissions due to transportation has left adverse effects on wildlife and environment around the globe. Once come into effect Green energy can play vital role in decreasing carbon emission further conventional wind turbines could be used along with bladeless vortex Technology for generation of electricity. Also the advanced electric vehicles charging system using inductive power transfer will altogether help in reduced emission levels.
\end{abstract}

Index Terms: Bladeless vortex, Electric vehicles [EV] charging through IPT, In-motion wireless power transfer, Selfhealing solar-phospholipid cells.

\section{INTRODUCTION}

It is known to all that vehicles and technology have advanced dramatically over the past 50 years, roadways have arguably failed to evolve at same rapid pace, especially from the user perspective. This is changing, as new technology have the potential to make radical changes to the construction, management and efficiency of road infrastructure. Consequently, the roads of the future may look and perform very differently to today.

With the upgrading world of technology the transportation and road facilities also needs to be upgraded for the betterment of life .If we look towards future few of the most important technological advancements would be the implementation of the phospholipid based solar-tech which would enables the self-healing of the highway roads due to the structural reforming properties of the synthetic molecule further these solar panels could also work with the currently available solar cells which displays information over surface mounted solar panels to provide visual information, these high-tech solar panels can also provide information of objects passing highways over a distance i.e. The roadways can also communicate with drivers, alerting drivers with visual messages to the presence of pedestrians in a crosswalk.

There are additional benefits as well, which is a built-in smart grid, major new investment and job creation, the economic benefits inherent in global leadership in building the most advanced clean energy infrastructure every dollar invested in renewable sources, ultimately generates returns, because the resource is not burned and lost. Further elaborating the topic of G-energy which is commonly known as Green energy will be collaborated with solar-tech to emphasize generation of energy by renewable resources only [1]. Under the category of renewable energy generation technology of bladeless vortex will be used as it has been proved to be very effective over cost and area further it will need less material, allowing us to provide electricity to more people at a lower cost while leaving a smaller environmental footprint. It won't kill birds and it won't make noise also conventional wind turbines will also be used along the highways for same purpose. Moving on to electric vehicles which is the innovation in trend still going on under various enhancements everyday will use the energy generated by solar-tech for moving over long range, currently inductive power transfer (IPT) or commonly known as wireless power transfer is the techniques which is in process having issues of magnetic interferences will be upgraded into in-motion cordless charging technology [2] which will enable users to charge their electric vehicles while travelling too, so that the biggest issue of decrease in battery charge percentage over distance will bother no more.

Thus combining all these technological advancements of phospholipid self-healing cells, in-motion wireless charging for electric vehicles and energy generation through bladeless vortex will lead to the concept of Green energy resulting in reduced carbon emissions

\section{ADVANCED PHOSPHOLIPID SOLAR CELLS}

Applying the most efficient ways for utilizing the solar energy plants could be the greatest inspiration; plants have evolved in such manners to get most from the solar energy: altering solar energy into stored energy and doing the same with effectiveness. The very common problem faced is that the rays of the sunlight can be really destructive for wide range of materials [3]. Sun rays leads to exponential damage of modules in usage which were developed to store it, but nature have evolved in its ways to overcome the same issue: plants have developed light capturing molecules which undergo continues break-down and assembles again and again, so as to form the basic 
Vol. 6, Issue 1, January 2017

structure that captures the sun's energy using the phospholipid cells the same process is imitated this molecule works in similar manner, it breaks down and then reassembles quickly, in plants the molecules which were used for photosynthesis, the reactive form of oxygen produced by sunlight causes the proteins to fail but the same protein quickly reassembles to restart the process. The phospholipid cells forms disk for structural support to other molecules that respond to light, in structures called reaction center which impart electrons when struck by photons. The disk and reaction centers are in solution where they attach themselves spontaneously to carbon nanotubes which are wire-like hollow pipes of carbon atom which practically are one-billionth of a meter, or about 10,000 times smaller than a human hair yet stronger than steel and conducting capability higher than copper[4]. These nanotubes hold together the phospholipid disk in uniform alignment to expose reaction centers to sunlight and they also provide channel for the electrons to flow which were knocked by the reaction molecules. the system includes seven different compounds i.e. carbon nanotubes, the phospholipid, the protein that build reaction centers which will generate electric current when exposed to right condition after assembling themselves into light harvesting structure the conventional photovoltaic cells seems an old idea now as many cost effective and efficient systems are being developed with higher flexibility as far as phospholipid cells are concerned their effectiveness is mark able as it has been tested with $40 \%$ efficiency practically further the collaboration of the solar road ways project with phospholipid cells will be the talk of future [5].

The statistical data by the solar roadways team provides us following figures [6].

112,610 square kilometers equals 43443.54 square miles. The report used data from 2001, so in 2016 (15 x 1/4 million acres) an additional 3.75 million acres have been turned into impervious surfaces. That's an additional 5859.38 square miles so all told, leaves 49302.92 square miles of impervious surfaces.

Removing $1 / 3$ for rooftops and that leaves 32,868.61 square miles of roads, parking lots, driveways, playgrounds, bike paths, sidewalks, etc., to work with.

If these impervious surfaces were replaced with Solar Road Panels, amount of electricity which could be generated In labs solar cell efficiency has exceeded 44percent but they're not cost feasible yet. For calculations they use commercially available solar panels which are cost competitive.

The efficiency of $18.5 \%$ is commonly available so for the calculations the following (conservative) assumptions have been made:

Solar cells have $18.5 \%$ efficiency

There is an average of only 4 hours of peak daylight hours per day $(4 \times 365=1460$ hours per year $)$

Sun power offers a 230 Watt solar panel rated at $18.5 \%$ efficiency. Its surface area is 13.4 square feet. If the entire $32,868.61$ square miles of impervious surfaces were covered with solar collection panels, then: $\left(\left(32,868.61 \mathrm{mi}^{2}\right) \times(5280 \mathrm{ft} . / \mathrm{mi})^{2}\right) /\left(13.4 \mathrm{ft}^{2} / 230 \mathrm{~W}\right)=$ $\left(\left(32,868.61 \mathrm{mi}^{2}\right) \times\left(27,878,400 \mathrm{ft}^{2} / \mathrm{mi}^{2}\right)\right) /\left(13.4 \mathrm{ft}^{2} / 230 \mathrm{~W}\right)$ $=\left(916,324,257,024 \mathrm{ft}^{2}\right) /\left(13.4 \mathrm{ft}^{2} / 230 \mathrm{~W}\right)=$ $15,727,953,665,337$ Watts or over 15.73 Billion Kilowatts

Considering only the average of 4 hours of peak daylight hours (1460 hours per year) this gives: 15.73 Billion Kilowatts x 1460 hours $=22,966$ Billion Kilowatt-hours of electricity.

Some important performance parameters are presented in Fig. 1.
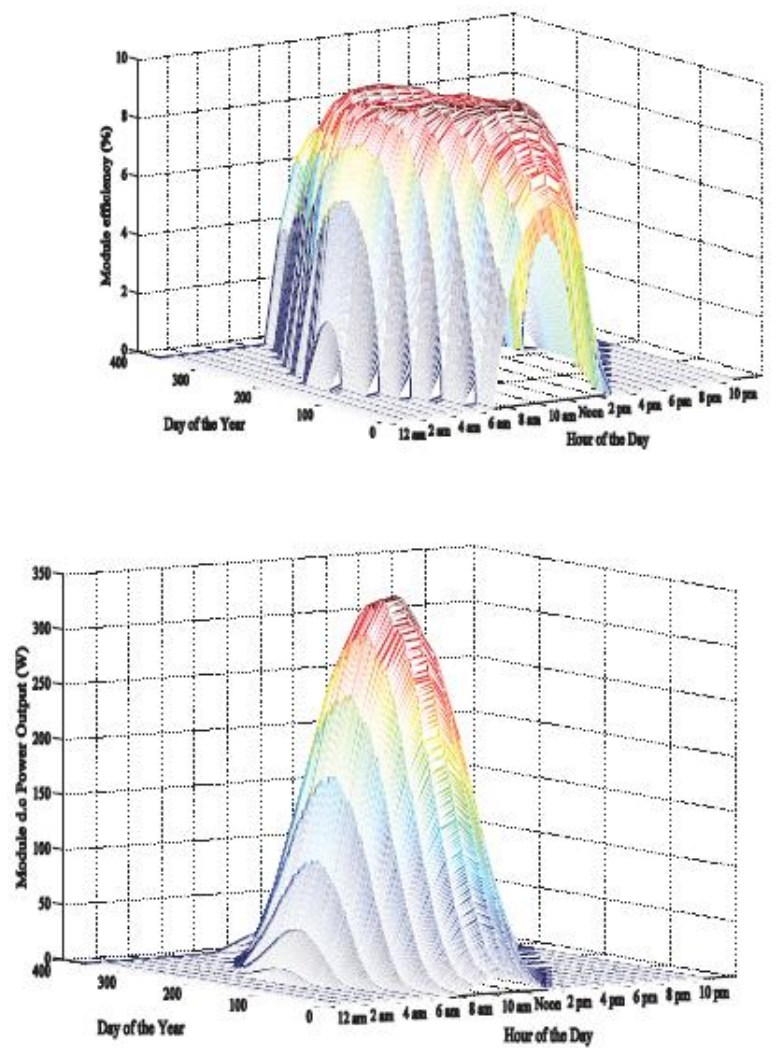

Fig1 Estimated Operating Efficiency of the Solar Road in Year 2015, estimated dc power output in the same year.

[1]

With current data it is estimated that approximately half(average estimate from different agencies is about $50 \%$ )of greenhouse gases causing global warming come from fossil fuel burning for purpose of electricity generation. Thus solar cells have the ability to reduce carbon emissions by half [7]. Another quarter percent comes from vehicle emission. Solar roadways provide advanced road facilities that can recharge electric vehicles anywhere 'even when in-motion such high tech solar cells could perform energy storage using virtual grid models.

Smart solar grid: Excess energy is sent to the grid during daylight hours. Then the power can be drawn back from the grid at night. The smart grid could be used instead of current centralized power stations providing sufficient power supply to parking lots, home, hospitals, educational 
institutes this will also provide easy access to all systems, Now such milestones are covered by providing large making maintenance and repair simple[8]. Such cells can battery size which does lead to increased cost and weight also work with weight sensors enhancing road safety of vehicle [11]. Thus to move away due to such issues inmeasures, solar panels can warn oncoming drivers. The motion charging is being introduced so that travel demand road panels in front of oncoming cars can tell the drivers is can be met using same battery size .

to "SLOW DOWN", in letters illuminated in the road's surface. The rest of the road can incorporate these sensors The survey from America says (as per July 2010) that the as well. The road could warn drivers of moderately Electric vehicles are not ecological in due to less supply or massed objects in the road, e.g., a person, an animal, a restricted supply of electricity to the areas [12].

fallen tree, a large rock, etc.

Life span of cells: These Solar cell are specifically engineered for road use. Panels are designed to last a minimum of twenty years. Solar cells are the limiting factor: they can continue to work up to 30 years, but they are less efficient toward the end of their life cycle.

Each panel can withstand great variations in temperatures. The electronic components are made to endure high temperatures. The microprocessors can endure temperatures from $-40^{\circ} \mathrm{F}\left(-040^{\circ} \mathrm{C}\right)$ up to $257^{\circ} \mathrm{F}\left(125^{\circ} \mathrm{C}\right)$.

Each Solar panel is hermetically sealed to protect the electrical components. The panels can be completely submerged, and the electrical components will be protected. This is a preventative measure for flash flooding. In the event of lightning, the entire system remains well grounded. Since the Solar panels are at ground level, lighting is far more likely to hit a nearby tree or other high point.

In case of An EMP (electromagnetic radiation) burst cells can shield against an EMP as with any other type of electromagnetic radiation: with shielding and proper grounding, which can mitigate or eliminate the effects of EMP. Shielding places a conductive surface between the source of the EMP and the electronic components. When the harmful radiation encounters a conductive surface, energy is transferred from the magnetic field into the conductive surface and shunted safely to ground [9]. This leaves less of the energy available to be transferred into the circuit. Protection diodes, which provide a low impedance path around low voltage circuitry, can also be utilized to minimize the effects of inductive voltage spikes.

\section{EVS AND AUTONOMOUS VEHICLES}

As by the data provided by ITF (international transport forum) 2010 statistics, carbon emission from transportation lead to $23 \%$ of total co2 emission and $30 \%$ of OCED CO $\mathrm{CO}_{2}$ emissions. Also it accounted for $15 \%$ of the total greenhouse gases emission [10]. Now it has become very important to transform the way we travel alternative vehicle technologies are developed to reduce dependence of fossil fuels. Different types of electrical transportation technologies are being investigated including electric vehicles, plug-n hybrid electric vehicles (PHEV), and hybrid electric vehicle (HEV) the market penetration of such vehicles is restricted due to product ownership cost as compared to traditional internal combustion (ICE) engines.

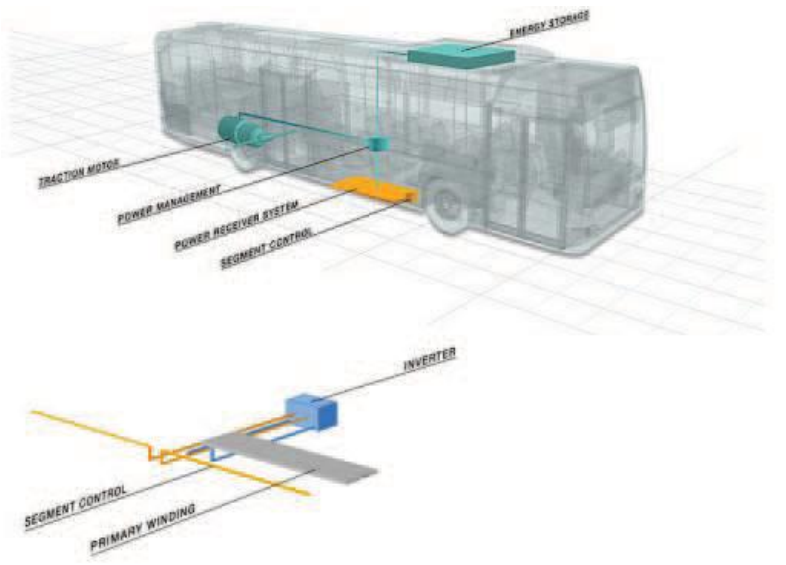

Fig 2. Wireless Power Transfer solution [13]

A true consequences of these cars would have to include the emissions of the power plants that supply their energy. When Department of energy researchers carried out such an analysis, they found that the results are very considerable with geography. By segregating country into different regions as per the power sources within each region - generally, a combination of coal, natural gas and nuclear energy, with a smattering of renewable energy thrown in. And check how a new fleet of electric cars would alter that supply. Nuclear and renewable, which together account for less than a quarter of the electricity supply, are "always on" sources. Their energy gets used up quickly for routine tasks,

Leaving little to no green energy left over to help charge a fleet of electric vehicles. In practical terms, this means that even if you live down the street from wind farm, its energy is already spoken for before you plug-in your plug. With nuclear and renewable taken out of the equation, it can be concluded that power for the fleets will have to come primarily from coal and natural gas. If you live in a place where natural gas is dominant, electric vehicles will reduce carbon dioxide emissions - in some cases by as much as 40 percent below that of an ordinary hybrid. Since the Solar Roadway creates and carries clean renewable electricity, EVs can be recharged at any conveniently located rest stop, or at any business places that incorporates Solar Roadways Panels in their parking lots (restaurants for instance). Owners can plug-in their cars in and recharge while they're eating or shopping. Engineers are even investigating ways to use mutual induction to charge EVs while they are driving down the Solar Roadway By the way using electric cars would 
eliminate most of the other half of the cause of global warming and could virtually wean the world off oil entirely. Businesses replacing coal power with solar power.

Drivers/car owners replacing their internal combustion engine vehicles with all-electric vehicles, charged by renewable energy. And this will be the beginning of the end of our dependency upon fossil fuels.

Results for in-motion charging: Results for the inmotion wireless power transfer Models were developed using the MATLAB/Simulink software and contain all vehicle components required for the various architectures Vehicle modeling results were validated by comparing model results to Argonne National Laboratory's (ANL) Downloadable Dynamometer Database for the EV and ICE vehicles over multiple drive cycles [14].

EV models were validated by modeling the Nissan Leaf, Mitsubishi i-MiEV, and the Ford Focus Electric.

The Toyota Corolla and conventional Ford Focus were used for validation of the ICE vehicle model. EV validation results showed that vehicle models were within $0.53 \%, 1.64 \%$, and $1.13 \%$ of expected energy consumption for the Leaf, i-MiEV, and Focus Electric respectively.

On surface level the WPT vehicles total savings compared to ICE vehicles were $49 \%$ and $58 \%$ for light duty vehicles respectively. Over the 14 year life of such vehicles operational cost of electric vehicles represent largest factor of total cost savings at $44 \%$.

Extending modeling work to evaluate infrastructure requirements on the urban sector, models were used to analyze minimal urban deployment. Based on 9,613 real world drive cycles, results shows that $97.8 \%$ of light duty vehicle trips can be satisfied by having a 25 mile range onboard battery and utilizing $50 \mathrm{~kW}$ in-motion charging only on interstate roadways [15], Fig. 3.

Comparatively, only $79.8 \%$ of real world drive cycles can be satisfied with a 25 mile range onboard battery and no in-motion charging. While this optimization assumed $100 \%$ coverage on interstate roadways, eliminating all inmotion charging on urban roadways represents a significant economic benefit.

In the U.S., the urban roadway system has 23.4 times more paved miles compared to the interstate system. Thus, the total capital costs for the deployment of the technology are more sensitive to the urban roadway coverage fraction than they are to the interstate coverage fraction. Satisfying $96 \%$ of real world drive cycles shows that in-motion WPT to $\mathrm{EVs}$ represents a promising alternative technology to traditional ICE transportation [11]. The levels of automated vehicles will vary from 1 and $11 \%$ in 2030 and between $7 \%$ and $61 \%$ in 2050 .
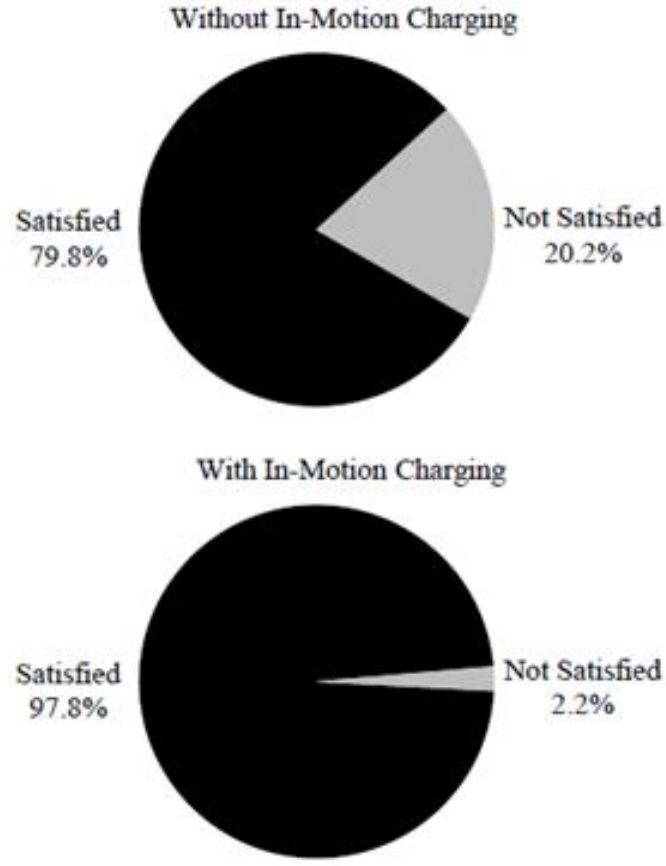

Fig 3. Comparison charts showing percent of 9,613 real world drive cycles satisfied using a 25 mile range EV when both $50 \mathrm{~kW}$ in-motion charging occurs only on interstate roadways and when no in-motion charging occurs [11]

\section{BLADELESS VORTEX}

Generation of electricity from tidal energy using conventional wind turbines has become an old concept now. The bladeless vortex is the 21 st century wind -mill it is more efficient, cost effective, and environmentally friendly way [16]. It contains no moving gears or bearings hence reducing manufacturing and maintenance drastically. Further huge reduction in carbon footprint under fewer supplies. It does not need any lubrication and is noiseless. Going by the stats it can help in reducing carbon footprint by $40 \%$, with decrement of $53 \%$ in manufacturing of such type off wind turbines as there will be having no blades, also leading to $40 \%$ cost reduction in global power generation.

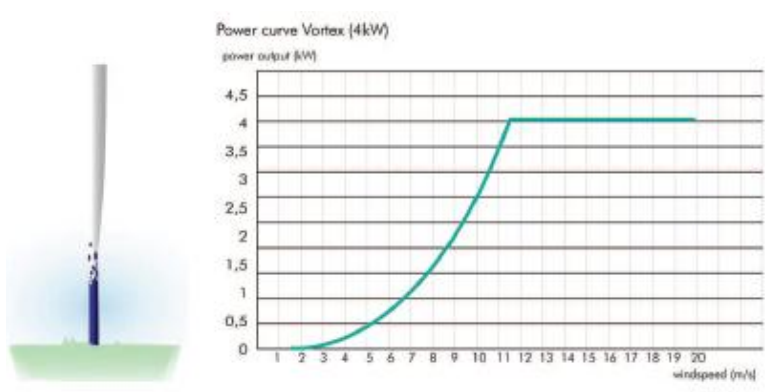

Fig 4. Vortex bladeless [16]

Vortex is basically a wind generator without blades. Instead of generating energy from rotational motion of a turbine, the vortex takes advantage of vorticity[17], an 
aerodynamic effect that occur when wind breaks against a solid structure as wind strikes vortex the structure starts to oscillate, and capture the energy that is produced.

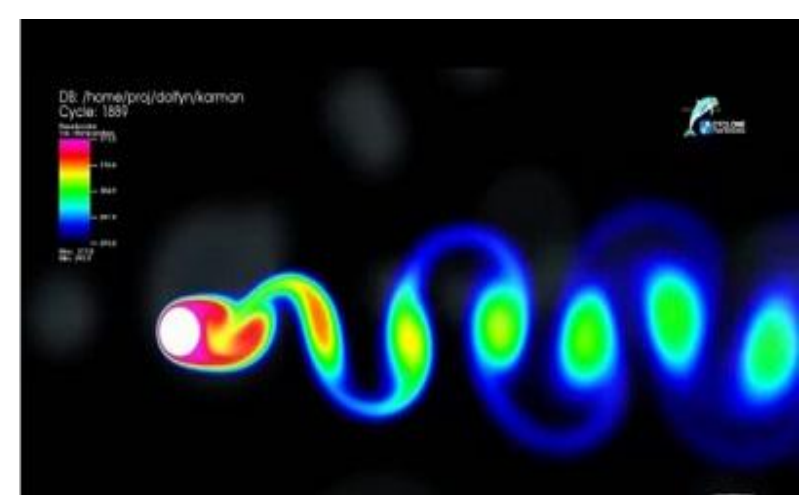

Fig 5. Air flow around bladeless vortex

\section{CONCLUSION \& FUTURE WORK}

In this paper, different techniques to building future roads are reviewed on the perspective of green technology applications. We can't wait any longer to find replacement to fossil fuels, which is rapidly decreasing. Our dependency on oil has long been a matter of national security and we shouldn't wait until is gone to decide the next step we have technology to solve this problem in relatively short period, which may be all we have left. In developing continents the major parts of geographical area is to be explored in terms of road cnnectivity.so instead of implementing the higher targets to develop roads we should merge ourselves towards green solar roads of the future.

Among all the technologies reviewed in this paper the phospholipid solar cells and in-motion wireless charging of electric vehicles are chosen out for detailed review, due to their suitability for green energy application in terms of both power and range level. The basic principle of each technology is explained. The latest development and research are summarized too.

\section{REFERENCES}

[1] Venugopal Prasanth, Natalia Scheele, Erwin Visser, Aditya Shekhar, Gautham Ram Chandra Mouli, Pavol Bauer, Sacha Silvestser "Green Energy based Inductive Self-Healing" ,2016 IEEE

[2] T.-E. Stamati and P. Bauer, "On-road charging of electric vehicles," in Transportation Electrification Conference and Expo (ITEC), IEEE, 2013, pp. 1-8.

[3] David L. Chandler, MIT News Office. [Online]. Available: http://news.mit.edu/2010/self-healing-solar

[4] Carbon-nanotubes. [Online]. Available: https://en.wikipedia. org/wiki/Carbon_nanotube

[5] F. Fan and Y. Lei, "Decomposition analysis of energy-related carbon emissions from the transportation sector in Beijing," Transportation Research Part D: Transport and Environment, vol. 42, 2016.

[6] Solar roadways. [Online]. Available: http://www.solarroadways. com/Specifics/Numbers

[7] A. Shekhar, S. Klerks, P. Bauer, and V. Prasanth, "Solar road operating efficiency and energy yield - an integrated approach towards inductive power transfer," in European Photovoltaic Solar
Energy Conference and Exhibition (EU-PVSEC), 2015, pp. 2614 2619.

[8] Solaroad. [Online]. Available: http://en.solaroad.nl/

[9] Solar roadways. [Online]. Available: http://www. solarroadways.com/Specifics/Electrical

[10] "Reducing Transport Greenhouse Gas Emissions Trends \& Data,' 2010. [Online]. Available: http://www.internationaltransport forum.org

[11] Braden J. Limb, Regan Zane, Jason C. Quinn "Infrastructure Optimization and Economic Feasibility of In-Motion Wireless Power Transfer" , 2016 IEEE

[12] Ashiq Guntupalli "INTELLIGENT HIGHWAYS (SOLAR ROADWAYS) - REBUILDING OUR INFRASTRUCTURE" in International Journal of Interdisciplinary Research and Innovation s.Vol. 2, Issue 4, pp: (11-19), Month: October - December 2014 IJIRI

[13] Mustapha DEBBOU, François Colet "Inductive Wireless Power Transfer for Electric Vehicle Dynamic Charging" ,2016 IEEE

[14] D. W. Gao, C. Mi, and A. Emadi, "Modeling and simulation of electric and hybrid vehicles," Proc. IEEE, vol. 95, pp. 729-745, 2007.

[15] B. M. Geller, "Increased understanding of hybrid vehicle design through modeling, simulation, and optimization," M.S. thesis, Dept. Mech. Engr, Colorado State Univ., Fort Collins, CO, 2010.

[16] Bladeless vortex. [Online]. Available: http://www.vortexbladeless.com

[17] Bladeless wind turbines may offer more form than function. [Online]. Available: https://www.technologyreview.com 